\title{
Influence of the central-to-peripheral arterial stiffness gradient on the timing and amplitude of wave reflections
}

\author{
Stacey S Hickson ${ }^{1}$, Wilmer W Nichols ${ }^{2}$, Yasmin ${ }^{1}$, Barry J McDonnell ${ }^{3}$, John R Cockcroft ${ }^{4}$, Ian B Wilkinson ${ }^{1}$ \\ and Carmel M McEniery ${ }^{1}$ on behalf of the ACCT Study Investigators
}

In individuals with compliant aortas, peripheral muscular artery stiffness exceeds central elastic artery stiffness. With aging, central stiffness increases with little change in peripheral stiffness, resulting in a reversal of the normal stiffness gradient. This reversal may reduce the wave reflection amplitude due to the movement of the major 'effective' reflection site further from the heart. To test this phenomenon, we investigated the relationship among arterial stiffness gradients (normal and reversed), wave reflection amplitude and reflection site distance. Subjects aged $\geqslant 50$ years were recruited from the Anglo-Cardiff Collaborative Trial. Central stiffness was assessed by carotid-femoral pulse wave velocity (cfPWV). In Study 1, peripheral PWV was also measured in the arm (carotid-radial pulse wave velocity) and, in Study 2, in the leg (femoral-dorsalis pedis). Reflection site distance was calculated from cfPWV and the reflected wave Tr. Subjects were dichotomized into those with a normal stiffness gradient (peripheral $>$ central PWV) or a reversed gradient (peripheral $<$ central PWV). In Study 1 , the reflection site distance was greater in subjects with a reversed gradient $(P<0.01)$, whereas time-to-reflection was lower $(P<0.001)$. Both the augmentation pressure $(P<0.001)$ and augmentation index $(P<0.05)$ were greater in subjects with a reversed gradient. In Study 2 , the augmentation pressure, augmentation index and reflection site distance were greater in subjects with a reversed stiffness gradient $(\boldsymbol{P}<0.01, P<0.05$ and $\boldsymbol{P}<0.01$, respectively), and time-to-reflection was not different between groups. A reversed arterial stiffness gradient is associated with an increased reflection site distance, and a paradoxical increase in reflected wave amplitude and augmentation index.

Hypertension Research (2016) 39, 723-729; doi:10.1038/hr.2016.64; published online 16 June 2016

Keywords: arterial stiffness gradient; augmentation index; central pulse pressure; pulse wave velocity; wave reflection

\section{INTRODUCTION}

Aortic stiffness, ${ }^{1,2}$ wave reflection ${ }^{3-7}$ and their surrogates, ${ }^{8-10}$ including central aortic pulse pressure (PP), ${ }^{11,12}$ are powerful independent predictors of cardiovascular risk and outcome. Wave reflections originate at arterial bifurcations and sites of impedance change or mismatch, such as the arterial taper and conduit artery terminations. ${ }^{13}$ These individual reflected waves then combine to form one apparent reflected wave, which combines with, and augments the initial and forward traveling pressure wave to form the measured pressure wave. Therefore, the central aortic pressure waveform is determined by the elastic properties and taper of the arterial tree, the amplitude of the reflected wave, and the time delay between the two waves (forward and reflected), which depends on the wave speed and distance to the major 'effective' reflection site. ${ }^{13,14}$
Central elastic arterial stiffness increases markedly with advancing age, whereas peripheral muscular arterial stiffness remains virtually constant. ${ }^{15,16}$ As a result, central stiffness can equal peripheral stiffness (impedance matching), or even exceed it (impedance mismatching), reversing the normal stiffness gradient. ${ }^{16,17}$ This has led to the suggestion that impedance matching (or mismatching) with central exceeding peripheral stiffness reduces the proximal wave reflection amplitude by shifting the major effective reflection site distally, resulting in a 'flattening' (followed by a decreasing) effect on the age-related augmentation index (AIx) curve that occurs in individuals over 60 years of age. ${ }^{17,18}$ However, this hypothesis has not been tested directly.

The aim of this study was to compare aortic wave reflection amplitude and reflection site distance between individuals with a

\footnotetext{
${ }^{1}$ Division of Experimental Medicine and Immunotherapeutics, Department of Medicine, University of Cambridge, Cambridge, UK; ${ }^{2}$ Division of Cardiovascular Medicine, Department of Medicine, University of Florida, Gainesville, FL, USA; ${ }^{3}$ Department of Biomedical Sciences, School of Health Sciences, Cardiff Metropolitan University, Cardiff, UK and ${ }^{4}$ Department of Cardiology, Wales Heart Research Institute, Cardiff University, Cardiff, UK

Correspondence: Dr CM McEniery, Division of Experimental Medicine and Immunotherapeutics, Department of Medicine, University of Cambridge, Addenbrooke's Hospital Box 98, Cambridge CB2 OQQ, UK.

E-mail: cmm41@cam.ac.uk

Received 4 November 2015; revised 29 April 2016; accepted 5 May 2016; published online 16 June 2016
} 
'normal' forward arterial stiffness gradient (peripheral pulse wave velocity $(\mathrm{PWV})>$ central $\mathrm{PWV}$ ) and those in whom this gradient is reversed (peripheral PWV < central PWV). Earlier studies used PWV measured in the $\operatorname{arm}^{17}$ or pressure waveforms measured in the carotid artery ${ }^{18}$ however, we chose to also use the aortic pressure waveform and PWV measured in the leg where the major 'effective' reflection site is located. ${ }^{13}$

\section{METHODS}

\section{Subjects}

All subjects and data were drawn from the Anglo-Cardiff Collaborative Trial (ACCT), a large, community-based investigation of the determinants of blood pressure and arterial stiffness across the adult age span. ${ }^{16}$ Participants with known peripheral vascular disease or atrial fibrillation were excluded from the analyses. For Study 1, we utilized data from 1567 healthy subjects aged $\geqslant 50$ years who had no history of diabetes, clinical cardiovascular disease and related medication. For Study 2, we invited a subset of 127 subjects from Study 1 to undergo additional measurements as described below. Finally, we examined data from 5117 subjects, ranging in age from 18 to 90 years old, to further examine the relationship between advancing age and wave reflection characteristics. We obtained approval from the local research ethics committee, and each participant provided written informed consent.

\section{Measurements}

Height and weight were assessed. Brachial cuff blood pressure was measured in duplicate and averaged in the nondominant arm according to the British Hypertension Society Guidelines, using a validated oscillometric device (HEM-711A-E, Omron, Matsusaka, Japan). After $15 \mathrm{~min}$ of supine rest, high-quality pressure waveforms were acquired by applanation tonometry using a SphygmoCor device (Atcor Medical, Sydney, NSW, Australia) at radial, carotid and femoral arterial sites, and in a subset of 127 subjects, at the dorsalis pedis arterial site. Using the integrated software, pulse wave analysis was applied to the aortic pressure waveform synthesized from the radial artery waveform (Figure 1). The system software used the second derivative of the pressure wave to identify the inflection point on the upstroke of the aortic pressure wave to determine the augmentation pressure (AP; the difference between the first and second systolic peaks of the aortic pressure waveform), augmentation index $(\mathrm{AIx} ; \mathrm{AP} / \mathrm{PP} \times 100)$, non-augmented pressure $(\mathrm{PP}-\mathrm{AP})$ and travel time $(\mathrm{Tr})$ of the aortic pressure wave from the heart to the major reflection site and back using a validated transfer function. ${ }^{19}$ Measurements were made on the nondominant side to minimize variability. ${ }^{20}$ Poor-quality waveform (according to the quality criteria embedded within the system software) instances of clearly erroneous values (that is, AIx $>50 \%$ ) or circumstances in which the system software was unable to calculate aortic characteristics were not included in the analysis.

The SphygmoCor device was also used to determine cfPWV by sequentially recording ECG-gated carotid and femoral artery waveforms as previously described. ${ }^{21}$ Carotid-radial PWV (crPWV) was determined from the carotid and radial waveforms. Similarly, femoral-dorsalis pedis PWV was determined from the femoral and dorsalis pedis waveforms in the subset of 127 subjects. The integrated software determined the foot-to-foot transit time between the respective pressure waves, and the path length was measured along the body surface using a tape measure as previously described. ${ }^{22,23}$ For cfPWV, the straight distance from the suprasternal notch to the carotid site was subtracted from that between the suprasternal notch and femoral site. ${ }^{23}$ The distance to the major 'effective' site (Lp) of wave reflection was calculated from cfPWV, as was the $\operatorname{Tr}$ of the reflected pressure wave from the reflection site to the heart $(\mathrm{Tr} / 2$; Figure 1$)$, as previously described..$^{24,25}$

\section{Data analysis}

The study was conducted in two main parts: a large retrospective study and a smaller prospective one. A further retrospective analysis $(n=5117)$ provided additional information on the wave reflection characteristics across the adult age span.

Study 1 was a retrospective analysis utilizing data from 1567 subjects who were $\geqslant 50$ years of age. Central stiffness was measured as cfPWV, and peripheral stiffness was determined in the arm from the carotid and radial (crPWV) pressure waves.

Study 2 was a prospective analysis conducted in a subset of 127 subjects from Study 1 . Because the reflected wave arrives mainly from the lower body, ${ }^{13}$ peripheral stiffness was measured in the leg, from the femoral-dorsalis pedis PWV, and central stiffness was measured as cfPWV.

In both studies, subjects were dichotomized into two groups, those with a normal arterial stiffness gradient (peripheral PWV $>$ central PWV) and those with a reversed stiffness gradient (peripheral PWV $<$ central PWV). All data were analyzed using SPSS software (version 20.0, SPSS, Inc., Chicago, IL, USA). Student's $t$-tests were applied to determine the significance between stiffness gradient groups, with $P<0.05$ considered significant.

\section{RESULTS}

\section{Study 1}

Table 1 contains the subject characteristics for Study 1 . The sample used for analysis included 1567 subjects (822 men and 745 women). Subjects with a reversed arterial stiffness gradient $(\mathrm{crPWV}<\mathrm{cfPWV})$
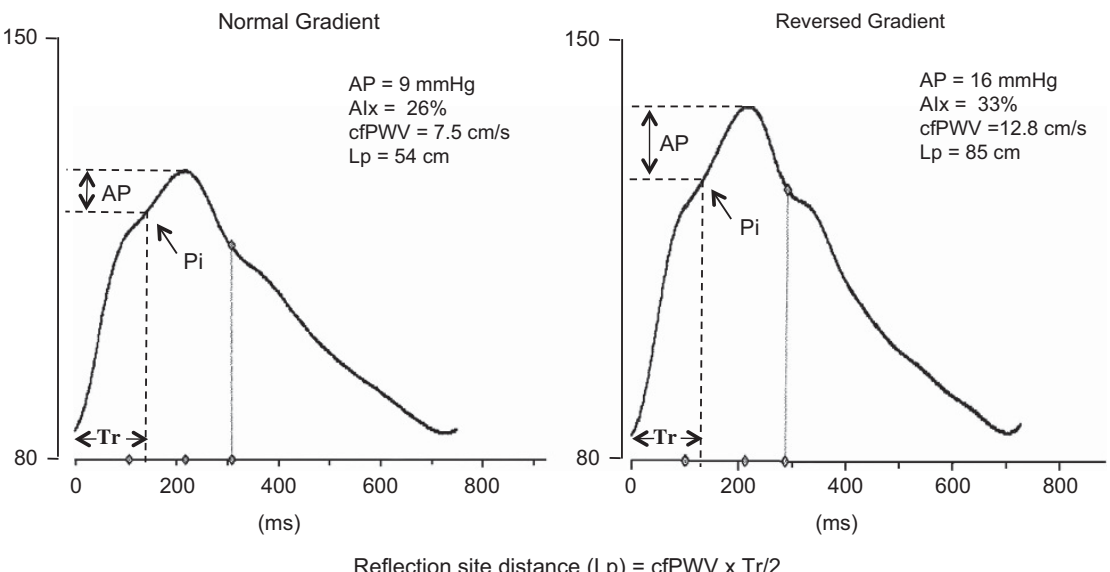

Figure 1 Synthesized aortic pressure waves in a subject (age 62 years) with a 'normal' arterial pressure gradient and another subject (age 79 years) with a 'reversed' arterial pressure gradient. AP is the augmentation pressure (reflected wave amplitude) and $\mathrm{Tr}$ is the round trip travel time of the forward wave from the ascending aorta to the major 'effective' reflection site and back. $\mathrm{Pi}$ is the inflection point or upstroke of the reflected wave. AP, augmentation pressure; Alx, augmentation index; cfPWV, carotid-femoral pulse wave velocity; $\mathrm{Tr}$, travel time. 
Table 1 Study 1: subject characteristics

\begin{tabular}{|c|c|c|c|}
\hline & $\begin{array}{l}\text { Normal gradient } \\
\begin{array}{c}\text { crPWV }>\text { cfPWV } \\
\mathrm{N}=528\end{array}\end{array}$ & $\begin{array}{l}\text { Reverse gradient } \\
\begin{array}{c}\text { crPWV }<\text { cfPWV } \\
\mathrm{N}=1039\end{array}\end{array}$ & Significance \\
\hline Age (years) & $62 \pm 6$ & $69 \pm 7$ & $P<0.001$ \\
\hline Gender (male/female) & $583 / 456$ & 239/289 & $P<0.001$ \\
\hline Height (m) & $1.67 \pm 0.08$ & $1.68 \pm 0.09$ & NS \\
\hline Weight (kg) & $71.4 \pm 13.7$ & $75.3 \pm 13.7$ & $P<0.001$ \\
\hline Brachial systolic BP (mm Hg) & $122 \pm 17$ & $135 \pm 21$ & $P<0.001$ \\
\hline Brachial diastolic BP (mm Hg) & $74 \pm 7$ & $76 \pm 8$ & NS \\
\hline Pulse pressure $(\mathrm{mm} \mathrm{Hg})$ & $48 \pm 14$ & $58 \pm 18$ & $P<0.001$ \\
\hline Central systolic BP (mm Hg) & $115 \pm 14$ & $126 \pm 17$ & $P<0.001$ \\
\hline Central diastolic BP (mm Hg) & $75 \pm 7$ & $77 \pm 8$ & $P<0.001$ \\
\hline Central pulse pressure $(\mathrm{mm} \mathrm{Hg})$ & $40 \pm 10$ & $49 \pm 13$ & $P<0.001$ \\
\hline Mean arterial pressure $(\mathrm{mm} \mathrm{Hg})$ & $88 \pm 9$ & $93 \pm 10$ & $P<0.001$ \\
\hline $\begin{array}{l}\text { Unaugmented central systolic } \\
\mathrm{BP}(\mathrm{mm} \mathrm{Hg})\end{array}$ & $102 \pm 11$ & $111 \pm 12$ & $P<0.001$ \\
\hline $\begin{array}{l}\text { Unaugmented central pulse } \\
\text { pressure }(\mathrm{mm} \mathrm{Hg})\end{array}$ & $27 \pm 6$ & $34 \pm 8$ & $P<0.001$ \\
\hline Heart rate (beats per min) & $63 \pm 9$ & $66 \pm 10$ & $P<0.001$ \\
\hline Augmentation index (\%) & $30 \pm 9$ & $31 \pm 10$ & $P<0.05$ \\
\hline $\begin{array}{l}\text { Augmentation pressure } \\
(\mathrm{mm} \mathrm{Hg})\end{array}$ & $13 \pm 6$ & $15 \pm 7$ & $P<0.001$ \\
\hline Carotid-femoral PWV $\left(\mathrm{m} \mathrm{s}^{-1}\right)$ & $7.5 \pm 1.1$ & $10.4 \pm 2.4$ & $P<0.001$ \\
\hline Carotid-radial PWV $\left(\mathrm{m} \mathrm{s}^{-1}\right)$ & $8.7 \pm 1.1$ & $8.1 \pm 1.3$ & $P<0.001$ \\
\hline Time-to-reflection (ms) & $78.3 \pm 3.6$ & $72.2 \pm 4.3$ & $P<0.001$ \\
\hline Distance to reflection site $(\mathrm{cm})$ & $52.1 \pm 8.7$ & $71.3 \pm 1.6$ & $P<0.001$ \\
\hline Total cholesterol $\left(\mathrm{mmol} \mathrm{I}^{-1}\right)$ & $5.4 \pm 1.0$ & $5.4 \pm 1.1$ & NS \\
\hline Triglycerides $\left(\mathrm{mmol} \mathrm{I}^{-1}\right)$ & $1.4 \pm 0.8$ & $1.6 \pm 0.9$ & $P<0.01$ \\
\hline
\end{tabular}

Abbreviations: BP, blood pressure; cfPWV, carotid-femoral pulse wave velocity; crPWV, carotidradial pulse wave velocity; NS, not significant.

Data are means \pm s.d.

were older $(69 \pm 7$ vs. $62 \pm 6$ years, $P<0.001)$ and more likely to have systolic hypertension (systolic pressure $\geqslant 140 \mathrm{~mm} \mathrm{Hg}$, diastolic pressure $<90 \mathrm{~mm} \mathrm{Hg}, 41$ vs. $14 \%, P<0.001)$ and higher triglycerides $\left(1.4 \pm 0.8\right.$ vs. $\left.1.6 \pm 0.9 \mathrm{mmol}^{-1}, P<0.01\right)$ than those with a normal arterial stiffness gradient $(\mathrm{crPWV}>\mathrm{cfPWV})$. In subjects with a normal stiffness gradient, cfPWV and crPWV were $7.5 \pm 1.1$ and $8.7 \pm 1.1 \mathrm{~m} \mathrm{~s}^{-1}$, respectively, and were $10.4 \pm 2.4$ and $8.1 \pm 1.3 \mathrm{~m} \mathrm{~s}^{-1}$, respectively, in subjects with a reversed stiffness gradient. Central systolic blood pressure and central PP were greater in subjects with a reversed stiffness gradient $(126 \pm 17$ vs. $115 \pm 14 \mathrm{~mm} \mathrm{Hg}$ and $49 \pm 13$ vs. $40 \pm 10 \mathrm{~mm} \mathrm{Hg}$, respectively) as was the distance to the site of wave reflection $(71.3 \pm 15.9$ vs. $52.1 \pm 8.7 \mathrm{~cm}, P<0.001)$, $\mathrm{AP}(15 \pm 7$ vs. $13 \pm 6 \mathrm{~mm} \mathrm{Hg}, P<0.001)$ and $\mathrm{AIx}(31 \pm 10$ vs. $30 \pm 9 \%$, $P<0.001)$. However, when AIx was adjusted for gender, height and heart rate, no difference between the normal and reversed stiffness gradient groups was observed. Unaugmented central systolic and PP were also greater in the reversed stiffness gradient group $(111 \pm 12$ vs. $102 \pm 11 \mathrm{~mm} \mathrm{Hg}$ and $34 \pm 8$ vs. $27 \pm 6 \mathrm{~mm} \mathrm{Hg}$, both $P<0.001)$ compared with the normal stiffness gradient group. In multivariable regression models, including age, gender, height, mean blood pressure and heart rate, a reversed stiffness gradient was independently associated with the reflection site distance, but not augmented pressure. Upon rerunning the model using central (aortic) PWV instead of the stiffness gradient per se, the results showed that central PWV remained independently associated with the reflection site distance and augmented pressure (Supplementary Table 1).
Table 2 Study 2: subject characteristics

\begin{tabular}{|c|c|c|c|}
\hline & $\begin{array}{l}\text { Normal gradient } \\
\begin{array}{c}f d P W V>c f P W V \\
\mathrm{~N}=83\end{array}\end{array}$ & $\begin{array}{c}\text { Reverse gradient } \\
\begin{array}{c}f d P W V<c f P W V \\
\mathrm{~N}=44\end{array}\end{array}$ & Significance \\
\hline Age (years) & $62 \pm 6$ & $69 \pm 7$ & $P<0.001$ \\
\hline Gender (male/female) & $32 / 51$ & $11 / 33$ & NS \\
\hline Height (m) & $1.66 \pm 0.09$ & $1.65 \pm 0.08$ & NS \\
\hline Weight (kg) & $70 \pm 11$ & $72 \pm 13$ & NS \\
\hline Brachial systolic BP (mm Hg) & $126 \pm 17$ & $138 \pm 16$ & $P<0.001$ \\
\hline Brachial diastolic BP (mm Hg) & $74 \pm 8$ & $76 \pm 7$ & NS \\
\hline Pulse pressure $(\mathrm{mm} \mathrm{Hg})$ & $53 \pm 12$ & $62 \pm 13$ & $P<0.001$ \\
\hline Central systolic BP (mm Hg) & $116 \pm 15$ & $126 \pm 12$ & $P<0.001$ \\
\hline Central diastolic BP (mm Hg) & $75 \pm 8$ & $77 \pm 7$ & NS \\
\hline Central pulse pressure (mm Hg) & $40 \pm 13$ & $51 \pm 10$ & $P<0.001$ \\
\hline Mean arterial pressure $(\mathrm{mm} \mathrm{Hg})$ & $93 \pm 11$ & $99 \pm 10$ & $P<0.01$ \\
\hline $\begin{array}{l}\text { Unaugmented central systolic } \\
\mathrm{BP}(\mathrm{mm} \mathrm{Hg})\end{array}$ & $107 \pm 13$ & $115 \pm 13$ & $P<0.01$ \\
\hline $\begin{array}{l}\text { Unaugmented central pulse } \\
\text { pressure (mm Hg) }\end{array}$ & $30 \pm 7$ & $35 \pm 7$ & $P<0.001$ \\
\hline Heart rate (beats per min) & $66 \pm 10$ & $68 \pm 7$ & NS \\
\hline Augmentation index (\%) & $28 \pm 11$ & $32 \pm 8$ & $P<0.05$ \\
\hline $\begin{array}{l}\text { Augmentation pressure } \\
(\mathrm{mm} \mathrm{Hg})\end{array}$ & $13 \pm 7$ & $16 \pm 6$ & $P<0.01$ \\
\hline Carotid-femoral PWV $\left(\mathrm{m} \mathrm{s}^{-1}\right)$ & $7.9 \pm 1.0$ & $10.9 \pm 2.0$ & $P<0.001$ \\
\hline Carotid-radial PWV $\left(\mathrm{m} \mathrm{s}^{-1}\right)$ & $8.3 \pm 1.0$ & $8.1 \pm 1.1$ & NS \\
\hline $\begin{array}{l}\text { Femoral-dorsalis pedis PWV } \\
\left(\mathrm{m} \mathrm{s}^{-1}\right)\end{array}$ & $9.9 \pm 1.1$ & $9.2 \pm 1.6$ & $P<0.01$ \\
\hline Time-to-reflection (ms) & $70.7 \pm 6.6$ & $68.6 \pm 7.0$ & NS \\
\hline Distance to reflection site $(\mathrm{cm})$ & $55.9 \pm 9.9$ & $74.6 \pm 14.9$ & $P<0.001$ \\
\hline Total cholesterol $\left(\mathrm{mmol} \mathrm{I}^{-1}\right)$ & $5.4 \pm 1.0$ & $5.7 \pm 1.0$ & NS \\
\hline Triglycerides $\left(\mathrm{mmol} \mathrm{I}^{-1}\right)$ & $1.3 \pm 0.8$ & $1.7 \pm 0.9$ & $P<0.01$ \\
\hline
\end{tabular}

Abbreviations: BP, blood pressure; cfPWV, carotid-femoral pulse wave velocity; fdPWV, femoral-dorsalis pedis pulse wave velocity; NS, not significant.

Data are means \pm s.d.

\section{Study 2}

Table 2 contains the subject characteristics for Study 2. Forty-three men and 84 women were included in the study analysis. Subjects with a reversed arterial stiffness gradient were older $(69 \pm 7 v s .62 \pm 6$ years, $P<0.001$ ) and more likely to have systolic hypertension (52 vs. 29\%, $P=0.014)$ and higher triglycerides $\left(1.3 \pm 0.8\right.$ vs. $1.7 \pm 0.9 \mathrm{mmol}^{-1}$, $P<0.01)$ than those with a normal stiffness gradient. In subjects with a normal stiffness gradient, cfPWV and femoral-dorsalis pedis PWV were $7.9 \pm 1.0$ and $9.9 \pm 1.0 \mathrm{~m} \mathrm{~s}^{-1}$, respectively, and $10.9 \pm 2.0$ and $9.0 \pm 1.5 \mathrm{~m} \mathrm{~s}^{-1}$, respectively, in subjects with a reversed stiffness gradient. Of those subjects with a reversed stiffness gradient based on femoral-dorsalis pedis PWV, the majority $(n=41 ; 93 \%)$ also had a reversed gradient based on crPWV. Central systolic and PP, and AP were higher in subjects with a reversed stiffness gradient $(126 \pm 12$ vs. $116 \pm 15 \mathrm{~mm} \mathrm{Hg}, 51 \pm 10$ vs. $40 \pm 13 \mathrm{~mm} \mathrm{Hg}$ and $16 \pm 6$ vs. $13 \pm 7 \mathrm{~mm} \mathrm{Hg}$, respectively, $P<0.01$ for all), as was AIx $(32 \pm 8 \%$ vs. $28 \pm 11 \%, P<0.05)$ and reflection site distance $(74.6 \pm 14.9$ vs. $55.9 \pm 9.9 \mathrm{~cm}, P<0.001)$. An example of the aortic pressure waves recorded in these two groups (normal and reversed gradient) is shown in Figure 1. AIx remained significantly higher in the reversed stiffness gradient group when adjusted for gender, height and heart rate. Time-to-reflection did not differ between groups $(70.7 \pm 6.6$ vs. $68.6 \pm 7.0 \mathrm{~ms}$ ). In addition, unaugmented central systolic and PP were also greater in those with a reversed stiffness gradient $(115 \pm 13$ vs. $107 \pm 13 \mathrm{~mm} \mathrm{Hg}$ and $35 \pm 7$ vs. $30 \pm 7 \mathrm{~mm} \mathrm{Hg}$, respectively, $P<0.001$ 
Study 1

Augmentation Pressure

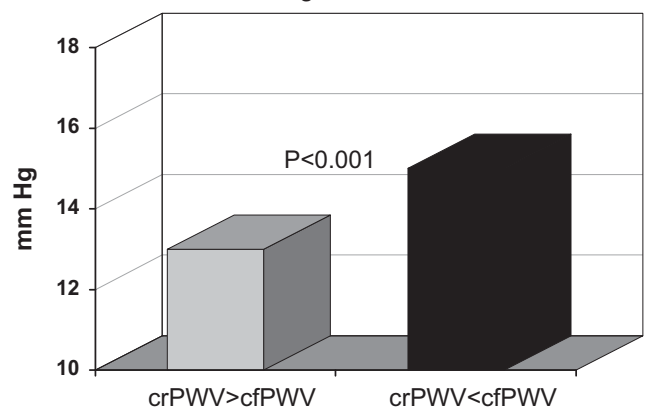

Reflection Site Distance

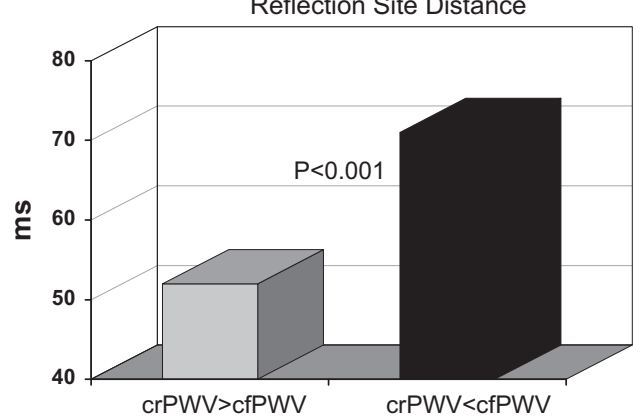

Study 2
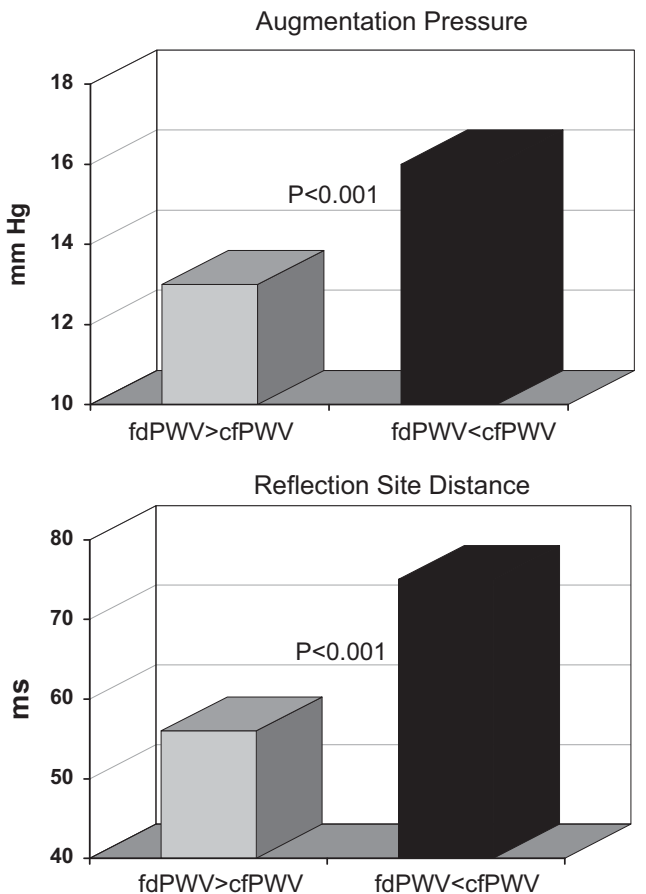

Figure 2 Composite data (augmentation pressure and reflection site distance) from all subjects in Study 1 and Study 2. Gray bars represent data from subjects with a 'normal' arterial stiffness gradient and black bars represent data from subjects with a 'reversed' arterial stiffness gradient. cfPWV, carotid-femoral pulse wave velocity; crPWV, carotid-radial pulse wave velocity; fdPWV, femoral-dorsalis pedis pulse wave velocity.

for both). Multivariable regression analyses revealed that central PWV, rather than stiffness gradient per se, remained independently associated with augmented pressure (Supplementary Table 2). Composite data, including the augmented pressure and reflection site distance from Study 1 and Study 2, are shown in Figure 2.

Age-related changes in central hemodynamics and reflection site distance were calculated from 5117 individuals, the results of which are illustrated in Figure 3. With advancing age, central PP and distance to the major reflection site increased exponentially $\left(R^{2}=0.47\right.$ and 0.41 , respectively, both $P<0.001)$ and paralleled each other, whereas AP increased linearly $\left(R^{2}=0.45, P<0.001\right)$. As expected, AIx increased linearly with age until 55-60 years of age, after which a flattening effect was observed $\left(R^{2}=0.49, P<0.001\right)$ with no decrease, even in the older subjects.

\section{DISCUSSION}

This study tested the hypothesis that the greater increase in central, rather than peripheral, artery stiffness with advancing age attenuates impedance mismatches between the central and peripheral arteries, leading to a shift in the major effective reflection site more distally in the lower body, in addition to an attenuation of the age-related increase in the wave reflection amplitude and AIx. We tested this hypothesis by dichotomizing a large number of healthy subjects into those with a normal arterial stiffness gradient (peripheral PWV $>$ central PWV) and those in whom the stiffness gradient was reversed (peripheral PWV $<$ central PWV), and then compared the reflection site distance and amplitude of the global reflected pressure wave.

When PWV in either the arm (Study 1) or leg (Study 2) was used as a measure of peripheral arterial stiffness, a reversed stiffness gradient was not associated with reduced proximal wave reflection or a lower AIx, despite the greater distance to the major effective reflection site, as previously suggested by Mitchell et al. ${ }^{17}$ and Vyas et al. ${ }^{18}$ The time
$(\operatorname{Tr} / 2)$ to the return of the reflected wave was lower in those with a reversed arterial stiffness gradient in Study 1, but was not significantly different between groups in Study 2, suggesting that the greater travel distance was offset by increased aortic stiffness. Moreover, reversal of the stiffness gradient was associated with a greater AP and a greater AIx in Study 2, indicating increased wave reflection amplitude, left ventricular afterload and myocardial oxygen demand in these individuals. It is highly likely that the increased reflected wave amplitude observed in individuals with a reversed stiffness gradient was driven, predominantly, by significantly higher central artery stiffness in these individuals. Unaugmented central systolic and $\mathrm{PP}$ were also increased in this group, indicating greater ascending aortic stiffness and incident wave amplitude. Moreover, central artery stiffness, rather than a reversed stiffness gradient per se, remained independently associated with the reflected wave amplitude in multivariable regression models. Nevertheless, it is highly unlikely that a reversal of the normal stiffness gradient in older subjects results in reduced proximal wave reflection, as suggested by a report from the Framingham Heart Study. ${ }^{17}$ The Framingham Heart Study investigators suggested that a reversal of the arterial stiffness gradient results from attenuated impedance mismatching between peripheral arteries and the central aorta, which then causes a distal shift in the major reflection site in the lower part of the body, attenuating the proximal wave reflection intensity and improving cardiovascular function. However, strictly speaking, frequency-dependent impedance of the central aorta and peripheral arteries is always mismatched because of the influence of wave reflection at lower frequencies. ${ }^{13}$ Impedance matching can only occur at higher frequencies where the spectrum is only minimally influenced by the wave reflection (that is, characteristic impedance). Although the current data are inconclusive, previous studies have suggested that the majority of wave reflections originate either in the descending aorta, at a single primary site occurring at the 

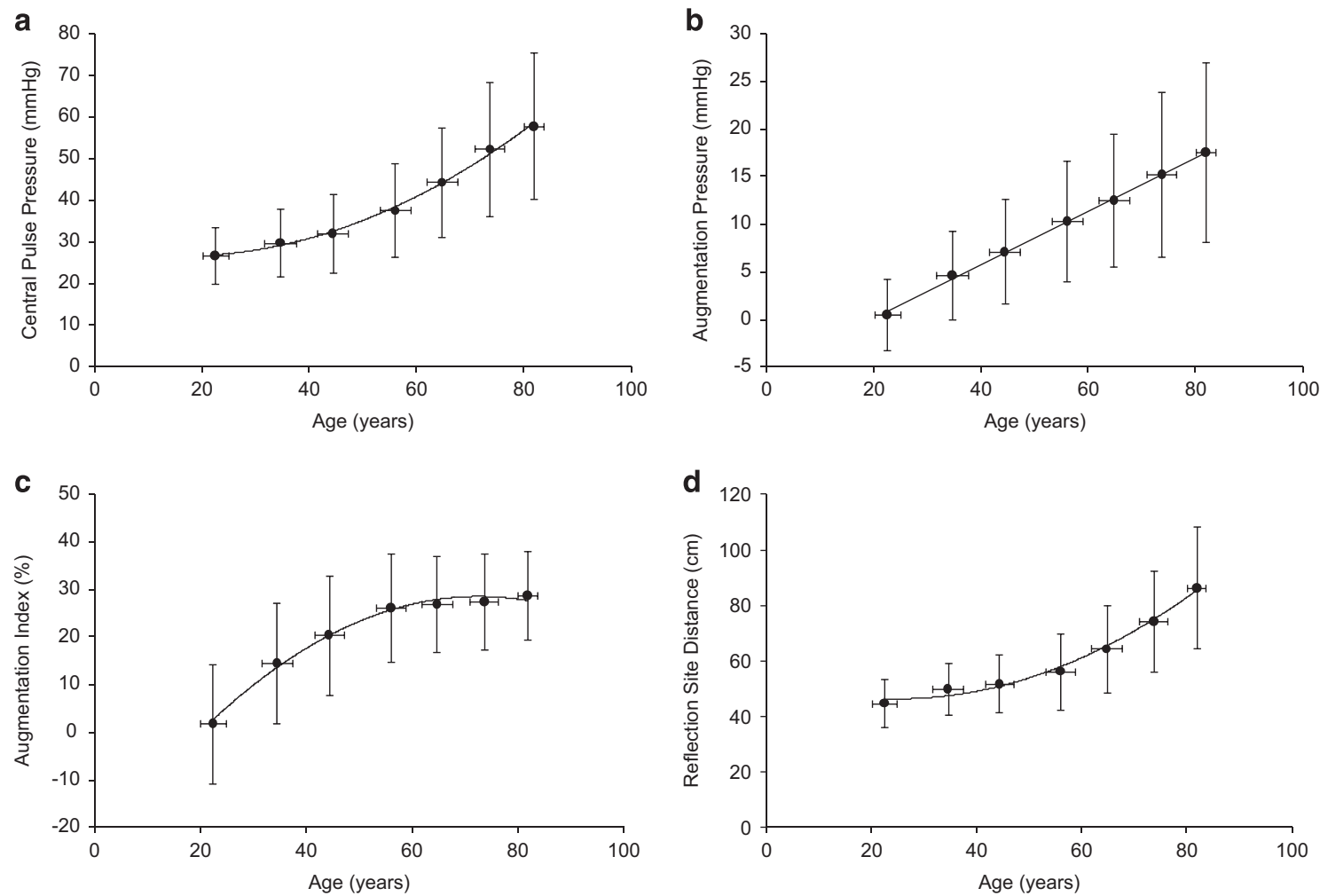

Figure 3 Age-related changes in (a) central pulse pressure $\left(R^{2}=0.47, P<0.001\right)$, (b) augmentation pressure $\left(R^{2}=0.45, P<0.001\right)$, (c) augmentation index $\left(R^{2}=0.49, P<0.001\right)$ and $(\mathrm{d})$ reflection site distance $\left(R^{2}=0.41, P<0.001\right)$.

aortic bifurcation, or between the aortic bifurcation and femoral artery site. $^{25-27}$

The contrast between the results of the current study and those of The Framingham Heart Study investigators ${ }^{17,18}$ may be due to erroneous estimation of the inflection point used to calculate wave reflection time, as suggested by Nichols et al. ${ }^{13}$ Mitchell et al. ${ }^{17}$ and Vyas et al. ${ }^{18}$ obtained the inflection point by visual inspection. In the current study, the inflection point was obtained automatically by the SphygmoCor device, which uses the second derivative of the aortic pressure wave, however, analyses based on the fourth derivative have also been used. ${ }^{28}$ Individuals $>60-65$ years of age often exhibit 'Type $D^{\prime}$ aortic pressure waves, which have no inflection point, ${ }^{13}$ and therefore cannot be detected visually. This is a clear limitation to the findings reported by Mitchell et al. ${ }^{17}$ and Vyas et al. ${ }^{18}$ The inflection point does, however, occur at peak aortic blood flow velocity in Type D pressure waveforms. ${ }^{13}$

To further examine the relationship between advancing age and wave reflection characteristics, the age-related changes in central hemodynamics and reflection site distance were calculated from a large number of subjects across the adult age span from the ACCT. These data showed a linear rise in AP and also an attenuation of the wave reflection amplitude with advancing age and an exponential increase in central aortic PP, which parallels the exponential increase in the reflection site distance. Because AIx is directly proportional to $\mathrm{AP}$ and indirectly proportional to $\mathrm{PP}$, the observed strengthening of the age-AIx relationship results from the incident pressure wave amplitude (which is directly related to ascending aortic stiffness), which increases to a lesser degree than the reflected wave amplitude (16 vs. 23\%). However, another hypothesis has been proposed that suggested that the reduced rate of rise of AIx beyond 60 years of age is attributable, at least in part, to a mathematical principle. Namasivayam et al. ${ }^{29}$ suggested that the ratio of two linear relationships, such as AP $v s$. age and PP vs. age (this group considered PP vs. age to be a linear relationship), results in a curvilinear trend (AIx vs. age). This mathematical phenomenon should, therefore, be considered for its potential contribution to the 'flattening' of the age-AIx curve.

Paradoxically, and in agreement with Mitchell et al., ${ }^{17}$ in the current study, reflection site distance increased with advancing age, and in agreement with Sugawara et al. ${ }^{26} \mathrm{did}$ so at a greater rate beyond 60 years. In addition, recent studies have reported a small increase in the length and diameter of the aorta ${ }^{30}$ and femoral arteries ${ }^{31}$ with advancing age, which may increase the travel distance of the forward and reflected wave as the central arteries stiffen, shifting the reflection site distally. However, these reports contradict a number of earlier studies that suggested a shift of wave reflection sites closer to the heart, ${ }^{28,32}$ rather than farther away. Although wave separation analysis is a more robust and accurate method for determining wave reflections, the distance to the major 'effective' reflection site in the current study was estimated from the wave speed and the measured time delay between incident and reflected waves. This method was proposed and validated in animals by Van Den Bos et al. ${ }^{24}$ and used in humans by Murgo et al. ${ }^{25}$ and Mitchell et al. ${ }^{17}$ Recently, a report by Westerhof et al. ${ }^{33}$ suggested that the reflection site distance cannot be accurately determined from the given formula due to a phase shift in the waveform at the reflection site. The phase shift would induce a time delay, resulting in a later return of the reflected wave and a falsely increased calculated distance to this site. However, the reflection site distance estimated using the method in the current study is comparable with the reflection site distance calculated using the classical method that uses the first minimum of the input impedance moduli spectra, commonly known as the quarter-wavelength method. ${ }^{13,25}$ The values for reflected wave $\mathrm{Tr}$ and $\mathrm{PWV}$ measured in the different 
arterial segments of the present study are similar to those previously reported for this age group using a variety of methods. ${ }^{15,17,34-37}$

\section{Limitations}

The current study has a number of limitations, including several methodological considerations. First, wave reflection is often considered to arise from a single point along the arterial tree (that is, the aortic bifurcation). However, the global reflected wave is a summation of numerous individual reflected waves, making the precise site of wave reflection theoretical. In the current study, the formula from Van den Bos et al. ${ }^{24}$ and Murgo et al..$^{25}$ was used to calculate the reflection site distance, and although reliable, it lacks the precision of wave separation analyses as used by Wang et al. ${ }^{5}$ and Segers et al. ${ }^{32}$ Moreover, PWV varies by vascular territory and, in general, is greater in the muscular arteries compared with the more elastic central arteries, ${ }^{16,38}$ although studies in animals ${ }^{39}$ and humans ${ }^{40}$ have demonstrated regional variations in PWV with the aorta itself. As such, the use of proximal aortic PWV in the calculation may underestimate the distance to the wave reflection site, because this occurs in the lower limbs, beyond the $\sim 50 \mathrm{~cm}$ length of the aorta. ${ }^{30}$ Because the aortic flow velocity was not assessed in the current study, we were unable to determine whether the reflection point occurred at the same time as the peak aortic blood flow velocity. In addition, we were unable to precisely determine whether readings not calculated by the SphygmoCor software or excluded on the basis of erroneous values arose from Type D pressure waveforms, where there is no identifiable inflection point. Finally, the measurements of PWV used in this study to dichotomize subjects into normal or reverse arterial stiffness gradients may have been influenced, somewhat, by the mean arterial pressure, which was higher in subjects with a reverse stiffness gradient. Therefore, a measure of arterial stiffness independent of (or adjusted for) mean arterial pressure may have been preferable.

\section{CONCLUSIONS}

Overall, the findings of this study in subjects aged $\geqslant 50$ years dispute the hypothesis that preferential stiffening of the central arteries attenuates the rise in aortic AP (and AIx) with age by distally shifting the site of wave reflection. However, reversal of the central-toperipheral stiffness gradient observed in older individuals remains important clinically, as it is associated with a greater central systolic pressure, $\mathrm{PP}$, and aortic stiffening and not a reduction in these parameters. These alterations in arterial properties and wave reflection characteristics place an additional load on the heart, and increases cardiac work and the myocardial oxygen demand, which increase cardiovascular risk. Moreover, reversal of the normal stiffness gradient along with an increased distance to the site of wave reflection may adversely affect the microvascular circulation due to increased pulsatile stress on these small vessels, leading to potential tissue and organ damage. Therefore, further studies are needed to investigate this question.

\section{CONFLICT OF INTEREST}

The authors declare no conflict of interest.

\section{ACKNOWLEDGEMENTS}

The ACCT Study Investigators, JRC, Zahid Dhakam, SSH, Julia Howard, Kaisa Maki-Petaja, BJM, CMM, Karen Miles, Maggie Munnery, Pawan Pusalkar, Christopher Retallick, Jane Smith, Edna Thomas, Sharon Wallace, IBW, Susannah Williams, Jean Woodcock-Smith and Yasmin. SSH is supported by the Cambridge Commonwealth Trust and the Cambridge Overseas Trust and IBW by a British Heart Foundation Senior Clinical Fellowship. This work was funded by the British Heart Foundation and in part through the National Institute for Health Research Cambridge Biomedical Research Centre.

Vlachopoulos C, Aznaouridis K, Stefanadis C. Prediction of cardiovascular events and all-cause mortality with arterial stiffness: a systematic review and meta-analysis. J Am Coll Cardiol 2010; 55: 1318-1327.

2 Ben-Shlomo $Y$, Spears M, Boustred C, May M, Anderson SG, Benjamin EJ, Boutouyrie P, Cameron J, Chen CH, Cruickshank JK, Hwang SJ, Lakatta EG, Laurent S, Maldonado J, Mitchell GF, Najjar SS, Newman AB, Ohishi M, Pannier B, Pereira T, Vasan RS, Shokawa T, Sutton-Tyrell K, Verbeke F, Wang KL, Webb DJ, Willum Hansen T, Zoungas S, McEniery CM, Cockcroft JR, Wilkinson IB. Aortic pulse wave velocity improves cardiovascular event prediction: an individual participant meta-analysis of prospective observational data from 17635 subjects. J Am Coll Cardiol 2014; 63: 636-646.

3 Chirinos JA, Zambrano JP, Chakko S, Veerani A, Schob A, Willens HJ, Perez G, Mendez AJ. Aortic pressure augmentation predicts adverse cardiovascular events in patients with established coronary artery disease. Hypertension 2005; 45: 980-985.

4 Nurnberger J, Keflioglu-Scheiber A, Opazo Saez AM, Wenzel RR, Philipp T, Schafers RF. Augmentation index is associated with cardiovascular risk. J Hypertens 2002; 20: 2407-2414.

5 Wang KL, Cheng HM, Sung SH, Chuang SY, Li CH, Spurgeon HA, Ting CT, Najjar SS, Lakatta EG, Yin FC, Chou $\mathrm{P}$, Chen $\mathrm{CH}$. Wave reflection and arterial stiffness in the prediction of 15-year all-cause and cardiovascular mortalities: a communitybased study. Hypertension 2010; 55: 799-805.

6 Weber T, Auer J, O'rourke MF, Kvas E, Lassnig E, Lamm G, Stark N, Rammer M, Eber B. Increased arterial wave reflections predict severe cardiovascular events in patients undergoing percutaneous coronary interventions. Eur Heart J 2005; 26: 2657-2663.

7 Mizuno A, Miyauchi K, Nishizaki Y, Yamazoe M, Komatsu I, Asano T, Mitsuhashi H, Nishi Y, Niwa K, Daida H. Impact of the augmentation time ratio on direct measurement of central aortic pressure in the presence of coronary artery disease. Hypertens Res 2015; 38: 684-689.

8 Kollias A, Rarra V, Karpettas N, Roussias L, O'Brien E, Stergiou GS. Treatment-induced changes in ambulatory arterial stiffness index: one-year prospective study and meta-analysis of evidence. Hypertens Res 2015; 38: 627-631.

9 Saji N, Kimura K, Yagita Y, Kawarai T, Shimizu H, Kita Y. Comparison of arteriosclerotic indicators in patients with ischemic stroke: ankle-brachial index, brachial-ankle pulse wave velocity and cardio-ankle vascular index. Hypertens Res 2015; 38: 323-328.

10 Schillaci G, Battista F, Settimi L, Anastasio F, Pucci G. Cardio-ankle vascular index and subclinical heart disease. Hypertens Res 2015; 38: 68-73.

11 Safar ME, Blacher J, Pannier B, Guerin AP, Marchais SJ, Guyonvarc'h PM, London GM. Central pulse pressure and mortality in end-stage renal disease. Hypertension 2002; 39: 735-738.

12 Roman MJ, Devereux RB, Kizer JR, Okin PM, Lee ET, Wang W, Umans JG, Calhoun D, Howard BV. High central pulse pressure is independently associated with adverse cardiovascular outcome the strong heart study. J Am Coll Cardiol 2009; 54: 1730-1734.

13 Nichols WW, O'Rourke MF, Vlachopoulos C. McDonald's Blood Flow in Arteries: Theoretical, Experimental and Clinical Principles. 6th edn. Hodder Arnold: London, UK, 2011.

14 Westerhof N, Sipkema P, van den Bos GC, Elzinga G. Forward and backward waves in the arterial system. Cardiovasc Res 1972; 6: 648-656.

15 Choi CU, Kim EJ, Kim SH, Shin SY, Choi UJ, Kim JW, Lim HE, Rha SW, Park CG, Seo HS, Oh DJ. Differing effects of aging on central and peripheral blood pressures and pulse wave velocity: a direct intraarterial study. J Hypertens 2010; 28: 1252-1260.

16 McEniery CM, Yasmin, Hall IR, Qasem A, Wilkinson IB, Cockcroft JR. Normal vascular aging: differential effects on wave reflection and aortic pulse wave velocity: the Anglo-Cardiff Collaborative Trial (ACCT). J Am Coll Cardiol 2005; 46: 1753-1760.

17 Mitchell GF, Parise H, Benjamin EJ, Larson MG, Keyes MJ, Vita JA, Vasan RS, Levy D. Changes in arterial stiffness and wave reflection with advancing age in healthy men and women: the Framingham Heart Study. Hypertension 2004; 43: 1239-1245.

18 Vyas M, Izzo JL Jr, Lacourciere Y, Arnold JM, Dunlap ME, Amato JL, Pfeffer MA, Mitchell GF. Augmentation index and central aortic stiffness in middle-aged to elderly individuals. Am J Hypertens 2007; 20: 642-647.

19 Karamanoglu M, O'Rourke MF, Avolio AP, Kelly RP. An analysis of the relationship between central aortic and peripheral upper limb pressure waves in man. Eur Heart $J$ 1993; 14: 160-167.

20 Martin JS, Borges AR, Christy JB 4th, Beck DT. Considerations for SphygmoCor radial artery pulse wave analysis: side selection and peripheral arterial blood pressure calibration. Hypertens Res 2015; 38: 675-683.

21 Wilkinson IB, Fuchs SA, Jansen IM, Spratt JC, Murray GD, Cockcroft JR, Webb DJ. Reproducibility of pulse wave velocity and augmentation index measured by pulse wave analysis. J Hypertens 1998; 16(12 Pt 2): 2079-2084.

22 Laurent S, Cockcroft JR, Van Bortel L, Boutouyrie P, Giannattasio C, Hayoz D, Pannier B, Vlachopoulos C, Wilkinson IB, Struijker Boudier HA. Abridged version of the expert consensus document. Artery Res 2007; 1: 2-12.

23 Weber T, Ammer M, Rammer M, Adji A, O'Rourke MF, Wassertheurer S, Rosenkranz S, Eber B. Noninvasive determination of carotid-femoral pulse wave velocity depends critically on assessment of travel distance: a comparison with invasive measurement. J Hypertens 2009; 27: 1624-1630. 
24 Van Den Bos GC, Westerhof N, Elzinga G, Sipkema P. Reflection in the systemic arterial system: effects of aortic and carotid occlusion. Cardiovasc Res 1976; 10: 565-573.

25 Murgo JP, Westerhof N, Giolma JP, Altobelli SA. Aortic input impedance in normal man relationship to pressure wave forms. Circulation 1980; 62: 105-116.

26 Sugawara J, Hayashi K, Tanaka H. Distal shift of arterial pressure wave reflection sites with aging. Hypertension 2010; 56: 920-925.

27 Latham RD, Westerhof N, Sipkema P, Rubal BJ, Reuderink P, Murgo JP. Regional wave travel and reflections along the human aorta: a study with six simultaneous micromanometric pressures. Circulation 1985; 72: 1257-1269.

28 Kelly R, Hayward C, Avolio A, O'Rourke M. Noninvasive determination of age-related changes in the human arterial pulse. Circulation 1989; 80: 1652-1659.

29 Namasivayam M, McDonnell BJ, McEniery CM, O'Rourke MF. Does wave reflection dominate age-related change in aortic blood pressure across the human life span? Hypertension 2009; 53: 979-985.

30 Sugawara J, Hayashi K, Yokoi T, Tanaka H. Age-associated elongation of the ascending aorta in adults. JACC Cardiovasc Imaging 2008; 1: 739-748.

31 Vermeersch SJ, Rietzschel ER, De Buyzere ML, De Bacquer D, De Backer G, Van Bortel LM, Gillebert TC, Verdonck PR, Segers P. Age and gender related patterns in carotid-femoral PWV and carotid and femoral stiffness in a large healthy, middle-aged population. J Hypertens 2008; 26: 1411-1419.

32 Segers P, Rietzschel ER, De Buyzere ML, De Bacquer D, Van Bortel LM, De Backer G, Gillebert TC, Verdonck PR. Assessment of pressure wave reflection: getting the timing right!. Physiol Meas 2007; 28: 1045-1056.
33 Westerhof BE, van den Wijngaard JP, Murgo JP, Westerhof N. Location of a reflection site is elusive: consequences for the calculation of aortic pulse wave velocity. Hypertension 2008; 52: 478-483.

34 van der Heijden-Spek JJ, Staessen JA, Fagard RH, Hoeks AP, Boudier HA, van Bortel LM. Effect of age on brachial artery wall properties differs from the aorta and is gender dependent: a population study. Hypertension 2000; 35: 637-642.

35 Di lorio BR, Cucciniello E, Alinei P, Torraca S. Reproducibility of regional pulse-wave velocity in uremic subjects. Hemodial Int 2010; 14: 441-446.

36 Ring M, Eriksson MJ, Zierath JR, Caidahl K. Arterial stiffness estimation in healthy subjects: a validation of oscillometric (Arteriograph) and tonometric (SphygmoCor) techniques. Hypertens Res 2014; 37: 999-1007.

37 Seidlerova J, Filipovsky J, Mayer O, Wohlfahrt P, Cifkova R. Positive effects of antihypertensive treatment on aortic stiffness in the general population. Hypertens Res 2014; 37: 64-68.

38 Nichols WW, Denardo SJ, Wilkinson IB, McEniery CM, Cockcroft J, O'Rourke MF. Effects of arterial stiffness, pulse wave velocity, and wave reflections on the central aortic pressure waveform. J Clin Hypertens (Greenwich) 2008; 10: 295-303.

39 Katsuda S, Takazawa K, Miyake M, Kobayashi D, Kusanagi M, Hazama A. Local pulse wave velocity directly reflects increased arterial stiffness in a restricted aortic region with progression of atherosclerotic lesions. Hypertens Res 2014; 37: 892-900.

40 Hickson SS, Butlin M, Graves M, Taviani V, Avolio AP, McEniery CM, Wilkinson IB. The relationship of age with regional aortic stiffness and diameter. JACC Cardiovasc Imaging 2010; 3: 1247-1255.

Supplementary Information accompanies the paper on Hypertension Research website (http://www.nature.com/hr) 